\title{
Dramatizing living-in-the-world: affective generalization in Drama-in-Education workshop
}

\author{
Shuangshuang $\mathrm{Xu}^{1}$, Jing $\mathrm{Wang}^{2^{*}}$, Luca Tateo, ${ }^{3}$
}

\begin{abstract}
Drama-in-Education workshops (DiE) emphasize on balancing between teacher's delicate structuring and participants' spontaneous exploration and creation in dramatic activities and thus can be a powerful liminoid space to scaffold and facilitate young people's development. Still, more researches are needed to dig into and understand such a dynamic and complex process happening in the workshop. In this article, we presented the theoretical background of conceptualizing drama as a hybrid cultural-aesthetic form to identify its potential in educational guidance. The perspective of developmental cultural psychology was introduced to frame DiE practice as a catalytic process working on releasing and transforming participants' developmental forces. The hierarchical levels of semiotic mediation in cultural psychology can help to capture participants' affective and cognitive generalizations in semiotic forms and to perform a micro-genetic analysis of the flow of participants' subjective experiences. We also provided a step-by-step analysis of a DiE practice working with young Chinese immigrants to illuminate our theoretical proposal.
\end{abstract}

Keywords Drama in Education; development; cultural psychology; semiotic mediation; affective generalization; aesthetics

\section{Declarations}

Acknowledgements The authors would like to thank Huiru Yan and Xinhuang Chen from Shanghai Theatre Academy and Xiaowen Li from East China Normal University for their support in devising and conducting the workshop. We are also grateful to Kari Mjaaland Heggstad and Sisi Zheng from Western Norway University of Applied Sciences and participants in living-room seminar organized by Jaan Valsiner in facilitating ideas for analyzing the empirical data.

Also many thanks to Enno von Fircks and another anonymous reviewer. Their constructive suggestions has helped us a lot in improving our work.

Funding: The author Shuangshuang Xu received funding from China Scholarship Council for her phd study in Denmark (No. 201808310229)

Conflicts of interests: The authors declared no potential conflicts of interest with respect to the research, authorship and/or publication of this article.

Ethics approval: The study with humans has been approved by University Committee on Human Research Protection, East China Normal University.

\footnotetext{
${ }^{1}$ Department of Communication and Psychology, Aalborg University, Denmark \& Ideas for the Basic Education of the Future, Shanghai, China. Email: Shuangsh_xu@163.com, Orcid: 0000-0002-3830-542X

$2 *$ Corresponding author, School of Psychology, East China Normal University \& Minhang Teenagers Practice Education Base, Shanghai, China. Email: jingd_wang@outlook.com

${ }^{3}$ Department of Special Needs Education, University of Oslo, Norway \& Federal University of Bahia, Brazil. Email:

Lucatateo@gmail.com. Orcid: 0000-0002-3207-6312
} 
Drama in education (DiE) has been an active branch of applied drama art feeding into the educational field. It is defined as "an art subject for co-creative experience and learning" in a group (Heggstad, 2019, p.2) balancing between teacher's structural organization and group's spontaneous improvisation without pre-given script and separate audience (O’Neill, 1995). Using DiE in the educational field generally refers to the process of teacher as a facilitator inviting participants to co-construct a fictive world and co-create dramatic encounters. Participants take on different functions of actors, audiences, playwrights, etc. both in and out of the drama world to explore complex issues meaningful for participants' own development. In this article, we are particularly interested in adopting DiE as a liminoid cultural space for young people to explore, create and transform meanings in their developmental transitions. The term of "liminoid" comes from Turner's distinction between "liminal" and "liminoid" (Turner, 1982). According to Turner (1982), liminal phenomena concerns with "calendrical, biological social-structural rhythms" (Turner, 1982, p. 54) with symbols carrying well recognized and respected meanings for the whole group and is integrated into the central social processes, while liminoid phenomena relies more on creative individuals and its symbols are more "personal-psychological" rather than "objective-social” (Turner, 1982, pp. 54).

Our main concern is to understand how a group of young people migrating from rural China to Shanghai would recognize themselves in the drama world and actively use their imagination, previous life experience and cultural resources to construct and transform meanings in the drama workshop. To achieve this goal, we first present a theoretical conceptualization of $\mathrm{DiE}$ as a hybrid form of cultural-aesthetic experiences connecting daily and artistic experience in one continuum. Following this vein, the potential of DiE workshops is highlighted as a liminoid zone for young people to actively construct, deconstruct and synthesize meanings to understand their own living-in-world experiences when challenged with uncertainty, discontinuity and ambivalence in developmental transitions. Then, we introduce developmental cultural psychology as a methodological framework to capture subjective participants' dynamic, complex and multi-layered meaning making processes in the DiE. In the last part, we also provide an analysis of DiE workshop with young Chinese migrants to illuminate and deepen our theoretical discussion.

\section{From everyday experience to art: DiE as a hybrid form of cultural-aesthetic experience}

DiE originates both in children's dramatic play and theatre/drama art. The two origins develop themselves further into two interrelating orientations in the field: educational orientation and theatre art orientation. These orientations constitute two poles in one continuum, along which DiE fluctuates. Rasmussen \& Wright (2001) proposed to adopt the broader term of "cultural aesthetic" to identify the nature of the continuum, stressing that the potential of drama in supporting and facilitating young people's development is undermined if drama is treated merely as an instrument for school curriculum learning or for professional art. This proposal requires to regard dramatic knowing and dramatization as spontaneous and wildly used symbolic activities in daily social and cultural practice. It calls for developing the potential of drama/theatre workshops as a liminoid space for participants to structure and restructure living experiences, both affectively and cognitively, by experimenting with dramatic forms. Dramatization should be understood as a general spontaneous coordinating process between inner and social world, and it is based on human's function of imagination and narrative thinking (Pascarella, Vicigrado, Tateo \& Marsico, 2020; Tateo, 2020; Bruner, 1986). As Heathcote (1984) articulated, dramatization exists as representation and pre-presentation of our ordinary life in our imagination, narration and action, and we use it daily to prepare ourselves by dramatizing a future scene, to enact and 
retell a story after an exciting or scaring event, and to live through books and movies vividly in our dreams and imagination.

The idea of relating artistic aesthetic experience back to everyday practice can be prominently traced in Dewey's book "Art as Experience" (Dewey, 1934). Dewey distinguished two forms of aesthetics: the primary and the artistic. The primary is connected with Dewey's concept of "an experience" as daily experiences with integrity, richness and coherence: "Every normally complete experience, every one that runs its own full course, is aesthetic in its consummatory phase" (Dewey, 1950, p. 56). The artistic, on the other hand, is conceptualized as intentional cultivation, concentration and intensification of the primary to make an experience clear and condensed rather than scattered and weakened. This aesthetic continuity from primary to artistic - from ground to mountain in Dewey's own metaphor - has freed art from its isolated and self-enclosed definition and calls for a re-interpretation of its function. From this perspective, art is firmly rooted in and originated from everyday social and cultural practice.

From an experience to artistic aesthetics, Dewey regarded artistic experience as a condensed, intensified and concentrated form of everyday experience. We would like to point out that the liminoid DiE's space is different from the daily experience, not only in a condensed and intensive way, but also as it invites participants to recognize, structure and narrate their affective experiences of living in this world in a qualitatively different language. This type of language has common characteristics in different art forms: it is to use sensuous materials to construct concrete figures. In this sensuous configuring process, the existential affectivity of living in this world can show itself, be perceived intuitively and be preserved for future sharing and reflection. Wang (2005a) analyzed the difference between emotions in daily life and emotions transformed in arts. He pointed out that, emotions become transformed in art by getting rid of direct connection with and pressing burden from concrete objects:

“By entering art, human being's affectivity goes into a free and active state. In this state, affectivity reaches the highest strength, and becomes a figure to look at. What we experience in artworks is exactly the forms and lives of affectivity itself. Art completes a miracle, that is making affectivity to appear in figures." (Wang, 2005a, p. 52, translated from Chinese by the authors)” .

It can be said that Dewey's metaphor of ground and mountain relates art back to daily experience, while Vygotsky’s metaphor of grape and wine reminds us the qualitative transformation of affectivity in art (Vygotsky, 1925). To summarize Dewey, Vygotsky and Wang, we are dealing with two different types of affective experiences in art: 1) affectivity as condensed and concentrated in art, e.g. a short 10-minute play can present a whole life of a man, thus the audience can experience various emotions in strong forms from "living" a whole life in the play; 2) affectivity as qualitatively transformed in art. As in Wang's analysis, through the artistic configuration of sensuous figures, we are able to get rid of the burdens bounded with concrete objects, and appreciate the form and value of affectivity of living in this world. That is, the object-bounded affectivity is transcended into existential affectivity endowed with values, and the values are experienced in the sensuous figures and illuminate the figures as possessing artistic beauty (Wang, 2005a). These two types of affectivity afford two forms of "Einfühlung” for participants. The German term of "Einfühlung" means "feeling into" and is translated as "empathy" into English. Einfühlung emphasizes on the process of “imaginary bodily perspective taking” (Ganczarek, Hünefeldt \& Olivetti Belardinelli, 2018, p. 141). von Fircks 
(2021) pointed out that Einfühlung, as encountering with and towards the foreign, enables us to cultivate and innovate our idea I. DiE and other art forms construct two layers of the foreign for participants to feel into: 1) the layer concerning the artwork's concrete contents and themes, which riches participants' experience by concentrating daily scattered ones into a gestalt one; 2) the layer concerning existential affectivity, which transcends concrete situations and emotions and reaches existential affectivity and values. In the former, we are encountering and feeling into the foreign's concrete experience, while in the latter we are feeling into the values of living in the world through the sensuous materials of the foreign's experiences.

In sum, the liminoid space of DiE's workshop should be considered as flexible and hybrid, which contains various forms of experiences on the cultural-aesthetic continuum concerning its local and open-ended nature of practice. Behind the idea of DiE as a hybrid cultural-aesthetic form hides an important theoretical turn, which calles for an understanding of the subjectivity of participants. That is, conceptualization of participants has changed from receivers of information, experience or skills to developing subjects, who actively use and produce meanings for their own lives. In dramatic construction and creation, participants are searching and appropriating all of their resources: real and fictive, individual and collective, past and future, to produce meaning to mediate their relationship with themselves and their worlds as active adaptation and pre-adaptation to future in irreversible time. DiE workshops are not utopians spaces isolated from daily life. Their attractiveness and potential tension stem from participants' life experiences: their vivid happiness, pain, confusion and expectation. Setting from the image of developing subjects, a good DiE workshop should start from participants' own living world and be designed in a way to scaffold "Einfühlung" on the two layers. It can reduce potential resistance and create affective basis for participants to relate, feel into the imaginary world and to rich and reflect their own existential experiences.

\section{Introducing developmental cultural psychology into investigation of DiE workshop}

The subjective turn prepared the theoretical foundation to use DiE as a cultural meaning-making space to guide young people's development in transitional periods. Focusing on participants' subjective development requires practitioners and researchers to consider how to structure DiE workshops not only as a playful ground for free experimenting, but also to devise DiE as an effective scaffolding for participants' development towards transitional challenges. We propose the perspective of developmental cultural psychology (Valsiner, 2012a; Zittoun, 2012) to analyze DiE as a liminoid cultural zone. Developmental cultural psychology can productively contribute in two ways. First, it understands participants as active agents striving for meaning making in their adaptation and pre-adaptation to transitional challenges, which constitutes a strong force and can be the basic and central point in devising and analyzing DiE workshops. Second, it focuses on semiotic production and mediation both at the interpersonal and intrapersonal level, which enables researchers to closely trace and analyze participants' complex, dynamic and multi-layered dramatic experience at a micro-genetic level.

Auto- and allo-catalysis: guiding participants' developmental force in DiE workshop

Cultural psychology considers development as a moving horizon, a dialectic between temporary stability and transitions. A transition is a process involving rupture, uncertainty, and ambivalence, from which grows a force to 
break, transform and transcend to a new organization of meanings. The tensional condition represents the dialectical force that produces the energy for change (Marsico \& Tateo, 2017). Facing a transition, the developing individual is an active subject striving to produce signs and synthesize meanings to mediate his relationship with himself and with his context (de Mattos \& Chaves, 2013). Development is based on a catalytic rather than causal relationship between the organism and the events occurring in the environment. Development is not a linear temporal process. Both maintaining the organism configuration, continuous self-recreation, and developing novel forms, innovation, are processes that require energy. In the life course, there are some events (allocatalytic) that can affect the person's life both in the direction of maintenance or innovation (e.g. some culturally set turning points in life, such as liminality moments). On the other hand, the person can actively create the conditions for a change (autocatalytic) when for example an adolescent creates a special personal atmosphere to develop new forms of identity (e.g. when making up her bedroom as special "cave" with particular music that promotes some existential course). More often, allo and autocatalytic processes work together during developmental transitions.

Using DiE workshops to work with young people in transition requires to considerate both autocatalytic and allocatalytic processes (Valsiner, 2008). According to Valsiner (2008), the autocatalytic process requires to examine how participants' own transforming state regulates and sets the conditions for them to relate with the drama world. The allocatalytic process relates to how DiE workshop can "break through" participants' hierarchical self-regulatory system and influence the participants' process of internalization and externalization. The work of any educational guidance is "finding appropriate catalytic inputs at appropriate times" in "the jungle of the zone of proximal development" (Valsiner, 2008, p. 136).

In developmental transitions, strong developmental forces derived from dealing with uncertainty, ambivalence and rupture requires to release and realize itself through active searching and integrating meaning across different spheres of experiences and across past, present and future. This strong force has its affective manifestation and constitutes the fuel for participants' exploration, creation and construction in the drama world. The power of releasing emotions in artistic experience can be seen in Aristotle's theory of catharsis. Dewey (1934) claimed that direct releasing emotions can not necessarily lead to artistic expression, as "Emotion is informed and carried forward when it is spent indirectly in search for material and in giving it order, not when it is directly expended (p. 70).” DiE's sensuous materials - objects, languages, bodily movement - also enable participants to configure, intuitively perceive, transform and reflect their developmental force both affectively and cognitively. The dynamic releasing and transforming process of developing force, which is condensed and generalized in affective and cognitive semiotics, should be the focus in analyzing participants' liminoid dramatic experience.

Semiotic hierarchy: micro-genetic analysis of subjective experiences in DiE

DiE's various involvement modes enable participants to both "live through" and reflect upon dramatic experiences at multiple levels. This complex multi-layered experience can be analyzed and encoded into hierarchical levels of semiotic mediation in the theoretical frame of developmental cultural psychology. Branco \& Valsiner (2010) distinguished four different levels of affective semiotics with an increasing degree of generalization: pre-semiotic feeling, specific emotion terms, generalized categories of feeling and hyper-generalized affective semiotic field. The construction of semiotic hierarchy basically involves two different generalization processes leading to the construction of different types of 
signs: schematization implies reducing complex experience into categorical point-like signs; and pleromatization implies transforming experience into complex field-like signs (Valsiner, 2020). Schematic construction of point-like signs is observed when participants search for specific signs to name and label their flow of experience (e.g. "X is Y"). Branco \& Valsiner (2010) used the concept of field-like signs to capture the fuzzy and undifferentiated nature of affective self-regulation. Especially, they proposed the notion of "hyper-generalized affective semiotic field" as the highest level of hierarchical integration to theorize the powerful guiding role of overwhelming beliefs and values, which can hardly be clarified in language. The interaction between schematized point-like signs and pleromatized field-like signs has the potential to produce complex hierarchical structure of signs, which differentiates, expand, but also constrains, participants' subjective flow of experience in the drama world.

In DiE workshop, participants are active meaning-making agents in a constant relationship of constructive internalization and externalization with their drama context. The meanings of the drama world- in forms of index, icons, or symbols - are deconstructed and selectively internalized into the individual inner system and the participants make their unique contributions to the group by creatively externalizing their unique individual meaning systems. A microgenetic analysis of semiotic production and mediation in the workshop enables the researcher to focus on the dynamic process and probe into how meanings from different sources and with different generalization levels are emerging, knitted, echoed and resonated into a web along with the unfolding of the drama world.

DiE can be an innovative qualitative methodology to investigate complex issues such as young people's values and beliefs (Rasmussen \& Wright, 2001), which are so ontogenetically internalized that can hardly be accessed through verbal language (Branco \& Valsiner, 2010). DiE workshops can be regarded as an ecological experimental field to observe participants' subjective semiotic flow among different levels of cognitive and affective generalization. The micro-genetic emergence of novel and alternative developmental paths and possibilities, mediated by the semiotic landscape of the workshop, constitutes meaningful data for nanopsychology: the focus on and thorough analysis of minimal selected data, which are deeply subjective and represent essential existential experience (Valsiner, 2018). Adopting the theoretical perspective of developmental cultural psychology of semiotic mediation allows to capture signs and symbols in their vivid movement "by contextualizing symbols in the concrete, historical fields of their use by "men alive" as they act, react, transact and interact socially" (Turner, 1982, p. 23). "Men alive" is the real object of psychology and psychology should be able to grasp human being in all of its fullness: "not as a personality but as a person, taking into account of all the richness of physiological, psychological and existential processes that characterize human life (Vassilieva \& Zavershneva, 2020, p.20)”.

So far, we have presented a theoretical framework to conceptualize DiE as a hybrid form of cultural-aesthetic experiences for young people to explore and integrate meanings for their subjective development in transitional periods. An appropriate design of DiE should be able to structure the workshop as an effective allocatalytic condition to resonate and scaffold the autocatalytic condition of participants' developmental forces. This resonance enables Einfühlung of participants, which forms the affective basis for a successful workshop. The releasing, configuration and transformation of developmental forces constitutes the underlying dynamics for dramatic exploration. We have also proposed that the hierarchical levels of semiotic mediation (Branco \& Valsiner, 2010) can help to capture participants' affective and cognitive generalizations and to perform a micro-genetic analysis of the flow of participants' subjective 
experiences. In the next section, we present and analyze a case study of DiE workshop to clarify and illuminate the theoretical framework. We particularly focus on the journey of participants' semiotic production in the workshop fueled by their developmental force in transitional periods and evolving in interaction with teachers as facilitators and the drama art. A close look is taken on what kind of signs and hierarchical levels of semiotic mediation are constructed and transformed in different episodes of the workshop; and on how DiE's cultural-aesthetic structure can facilitate participants to migrate among different levels of generalization.

\section{Introduction of the workshop "Castle in a box"}

The workshop title is "Castle in a Box" and it has been formerly described and analyzed in Xu, Li \& Wang (2018). Here, we focus on the semiotic flow emerging in the workshop and try to re-interpret the data from the perspective of developmental cultural psychology of semiotic mediation. We first provide a brief introduction of the background and structure of the workshop. Then, we summarize the main findings from our previous work as a basis for our reinterpretation.

The workshop is a part of the "Active development course" used to help a group of young people migrating from rural areas to the town of Shanghai in China. The group was selected by a NGO to receive an one-year vocational training in Shanghai. It consisted of 32 teenagers between 16 and 22 mainly from poor rural families. Most of the young people dropped out their studies and were confused about their careers. The group was divided into two sub-groups of 16 students each. The two groups took turns to attend classes and trainings. Differently from one-to-one psychological counselling, "Active development course" mainly focuses on the group level. It aims to exploring effective ways to construct a cohesive group and to use the group dynamics to facilitate individual's subjective developmental potential (Wang, 2018). The course was held once a week and lasted for one year. It was designed to be very sensitive to the group's developmental needs. DiE was introduced in the midst of the course, during the first semester, when the group finished theoretical learning and was faced with the challenge of being interviewed for internship opportunities.

Internship was a second transition from school to job market, following the first transition of migrating from rural China to a big city. Migration from one world to another creates huge gaps and discontinuity. In this gap, not only the environment is changed, but also the psychological expectation, interpersonal connections and supporting resources are renewed and need to be re-constructed. At that time, participants experienced huge difficulties and frustrations. They “felt meaningless in daily life and couldn't devote themselves fully to daily life activities” (Xu, Li \& Wang, 2018, p. 143). This existential confusion, uncertainty and anxiety constitutes huge force for semiotic exploration in DiE workshop. The workshop we used was adapted from a theatre in education workshop "Suitcase" (DICE Consortium, 2010), which consists a 2-hours session for each group. Workshop was held in their classroom and was video recorded for later transcription. Informed consent has been signed and collected from the participants. All names are fictional and photos have been processed so that no information can be used to identify the participants. As an example, we focus on one of the two groups' DiE experience.

The whole workshop can be divided into 8 steps for the sake of analysis: \#0 warm up; \#1 constructing the room; \#2 teacher-in-role and scene performance; \#3 participants enacting the dramatic event of tearing newspaper; \#4 narrating the day he left home; \#5 using still image to construct the future; \#6 poetic narration; and \#7 writing a letter for 
reflection. Two teachers (T1 \& T2) took turns to share the responsibility as facilitator and acting in role. The objects used and the space structure of the room is described in Fig. 1. A detailed description of the segments follows:

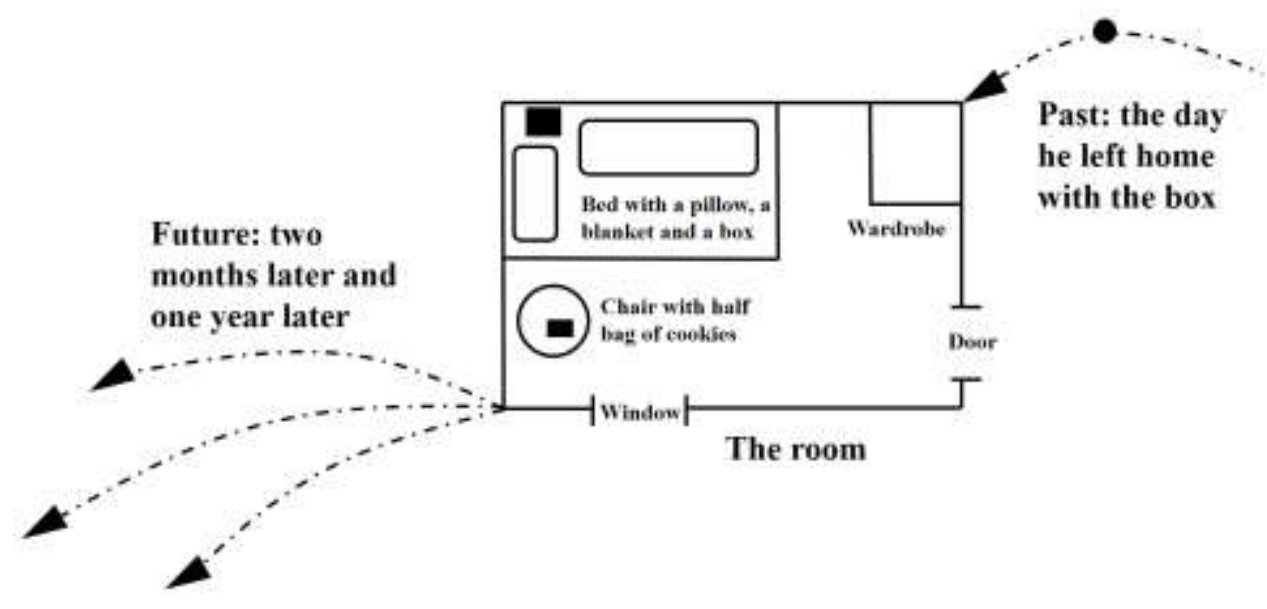

Fig. 1 Final setting of the room with extended timelines

\#0. Warm-up: 5 min. Empty room without setting. The whole group standing in a circle and holding hands. T1 inviting a voluntary participant to stand outside the circle and try to enter the circle with resistance from the group, and then stand inside to try to be out.

\#1. Constructing the room: 20 min. T2 sharing with the group a story with limited information about the character: He came to Shanghai from other areas and now lives in a small room with shared toilet and kitchen with others. He came here not very long. Asking help from the group to know better the character and inviting the group to explore the story together. T1 using tape and objects to mark the character's room (a chair, a simple bed with pillow and a box on it) and leading the group to imagine and describe the following things: door, bed, wardrobe, chair and an opened bag of cookies. Inviting the group to imagine the shape, texture, condition of the objects and the surrounding environment of the room. The box was the key object for the workshop. Teacher inviting the group to guess what would be in the box without opening it. Inviting the group to step into the room and describe what can be seen from his window.

\#2. Teacher-in-role (TiR) and performance: $20 \mathrm{~min}$. The actions designed for T1's performance is described as following: He walks with newspaper under his arm and stops at the door, picks up the sheets drawn by the participants, opens the door and enters the room, locks the door, looks from the window, lies on his bed. Get up. Interact with the objects aside bed (Fig 2). Eat the cookies. Hold and then open the box (Fig. 3), look at his old drawing of Shanghai, try to draw, feel angry, stop drawing. Pause. Read newspaper. Take notes. Pause. Weep with hands covering his face and keep still (Fig. 4). T2as facilitator claps her hands as a signal for closure of performance. T2 invites a participant to enter into the room and examine the objects to make sure the group has seen them clearly. Asking the group what have happened in front of you, what did you see. 


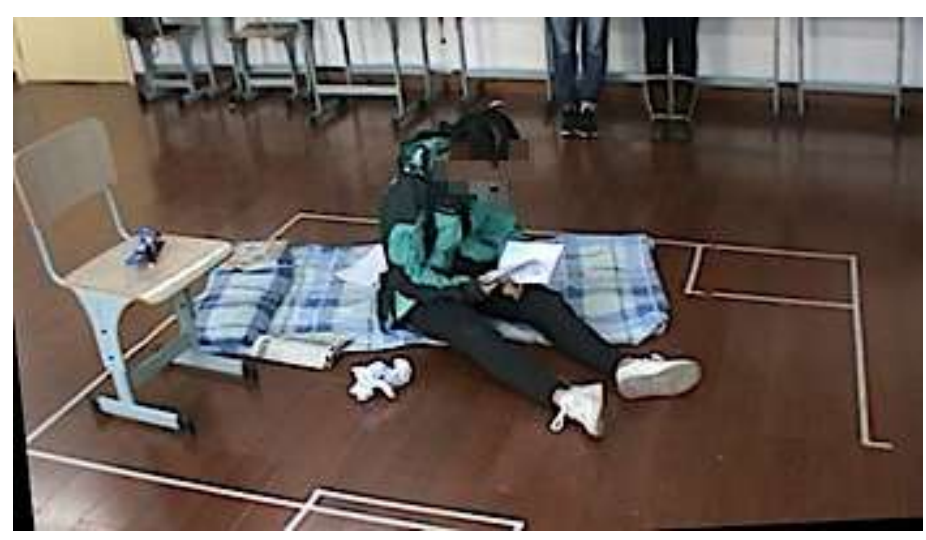

Fig. 2 TiR interacting with objects suggested by the participants: a diarybook

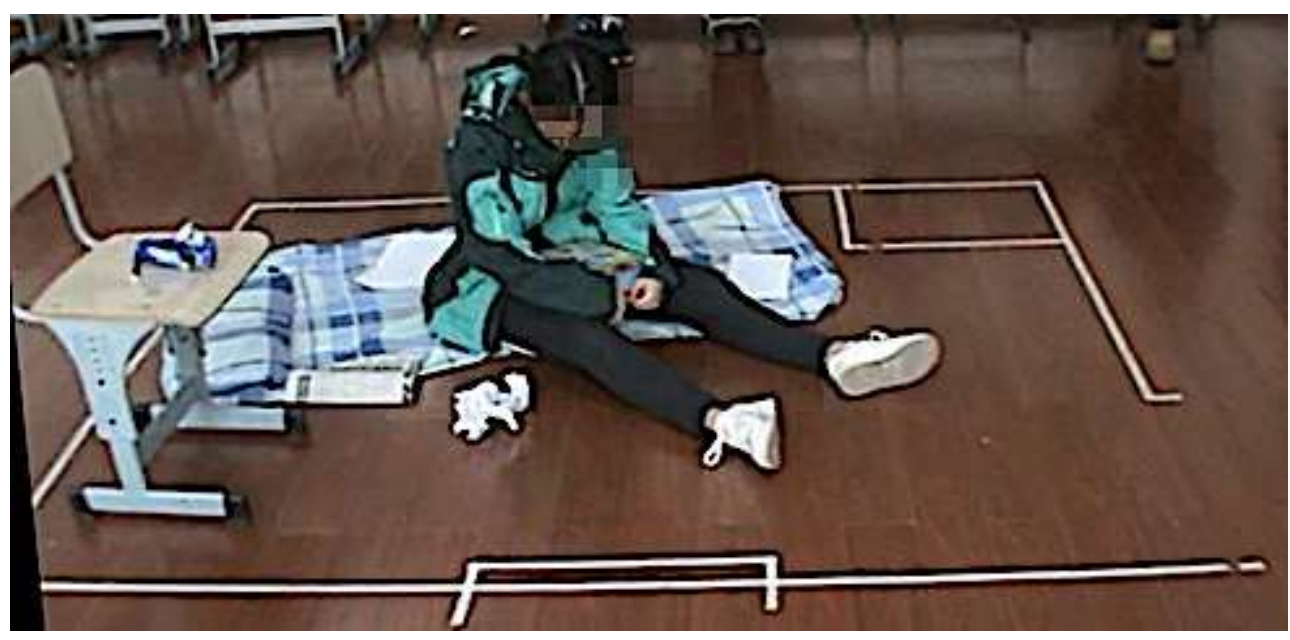

Fig. 3 TiR holding the box as a key object

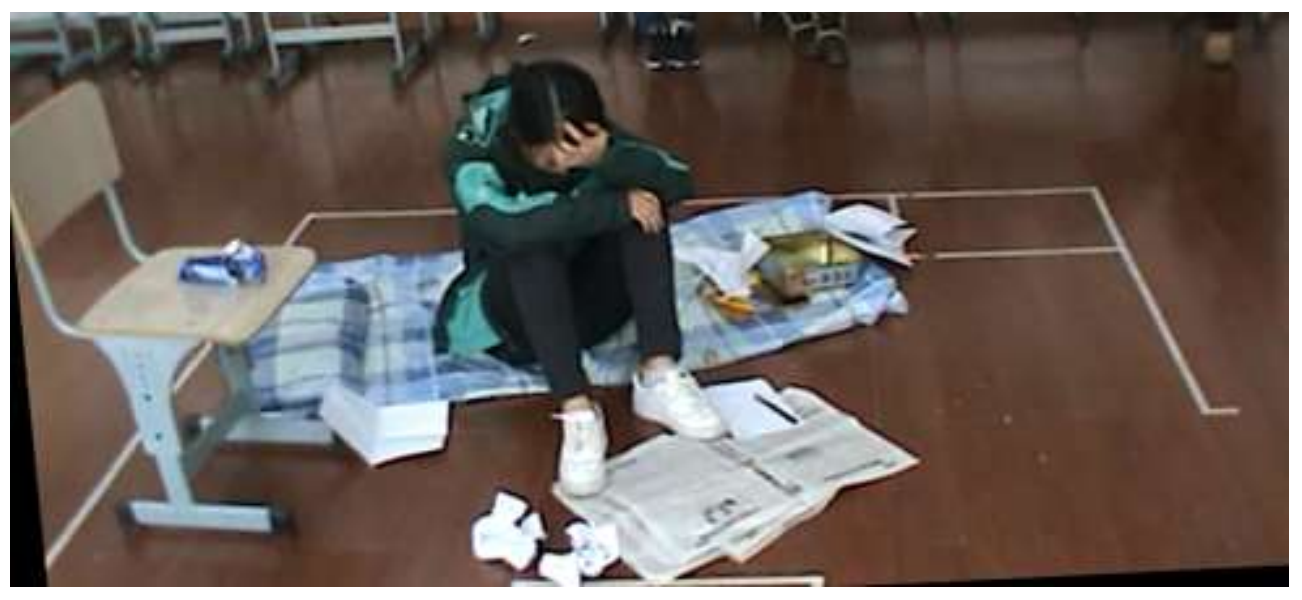

Fig. 4 TiR weeping in hands as closure of performance 
\#3. Enacting the dramatic event of tearing newspaper: 10 min. T1 taking off the coat and leaving the room. T2 as facilitator narrating that the man sat there for a long time, and then he picked up the newspaper and tore it. How did he tear the newspaper? Inviting participants to enter into the room, put on his jacket and enact the moment of tearing newspaper into pieces.

\#4. Narrating the day he left home: $20 \mathrm{~min}$. T1 as facilitator inviting the group to explore the story along the timeline (using the tape to mark the timeline extending from two sides of the room to represent past and future). Inviting the volunteers to stand on the past timeline, hold the box, imagine and narrate what happened the day he left home with the box.

\#5. Still image constructing the future: 25 min. Dividing the group into three sub-groups. Each sub-group creating two tableaus to explore what would happen two months later and one year later. Sub-groups taking turns to present in front of the big group. T2 as facilitator interviewing the big group about what did they see and also interviewing the subgroup what they were thinking as characters in the tableau and why it happened.

\#6. Poetic narration: 5 min. T1 gathering the group to sit around the character's room. T1 narrating poetically with music about one day the man sitting in a park and seeing a little boy enjoying building sand castle.

\#7. A letter: $10 \mathrm{~min}$. T1 inviting the group to write a letter from the perspective of the man to himself in the past, present or future. Inviting the group to put their letter on the timeline when they finish. T1 randomly choosing some to share with the group.

\section{Analysis from the perspective of developmental cultural psychology}

During the workshop, participants' meaning making process is characterized as full immersion, mainstream storyline overtaking personal voices and reflection in the language of ideology ( $\mathrm{Xu}, \mathrm{Li} \& \mathrm{Wang}, 2018$ ). To be more specific, in the episode \#1 of context's construction, \#2 performance narration and \#3 tearing newspaper, the group showed a great interest and they entered into the drama world rather quickly with a strong empathy with the main character. In the episode \#5 constructing the past and future, the symbol of “dream” facilitated, but also constrained, the group's construction, which led to an ideological expression in the last episode \#7 writing a letter. Based on the previous work, our analysis in this article divides the episodes into three parts and takes a closer look to reveal participants' semiotic dynamics in such a complex process.

\section{Part 1 mutual feeding of as is <> imaginary as if}

During the episodes \#1, 2 and 3, the group quickly distanced from their here-and-now mundane condition by working on imagining what the room was like. From episode \#1, we report participants' collective description of the door and a segment of interaction between the group and T1 as facilitator around the wardrobe. In this segment, T1 used gestures and concrete questions to support the group to imagine the objects. She validated the group's inputs in a positive and firm way but also selectively amplified and restrained certain interpretations from the group. Participants' imagination 
reflected their perception of the main character's self-world relationship. The character is interpreted as a man living in not very good condition, while the world was presenting itself with high degree of materiality.

Summary of participants' inputs about the door's appearance: wooden, with painting falling apart, it is yellow/green/dark red, not very smooth. On the door, there is an invoice requesting rent by the landlord, with his room number: 807. There are small advertisements: changing locks, changing gas, sewing pipes. Under the door there are leaflets, and advertisement for selling apartments: Shanghai Garden, 50000 Yuan per square meter, with north-south ventilation, 120 square meters in total, in the district with best schools and free parking space.

\section{T1-group Interaction about the wardrobe:}

T1: At the right side of the room, there is a wardrobe, This wardrobe, is as high as me (using her hand to mark the height). How many layer of drawers do you think it has?

Group: 3 drawers.

T1: 3? Ok, there are 3 layer of drawers, one, two, three (using her hand gesture to mark the three drawers). What do you think would be in the first drawer? (imitating opening the drawer at the top)

Group: ... (Cant clearly identify)

T1: Cash?

Group: Identity card/ one million Yuan!

T1: Ok. Look at this room. Will there be one million Yuan?

Group: 100 Yuan.

T1: How much do you think?

Group: 100 Yuan!

T1: ok, there is 100 Yuan. Let's see the second drawer. Open it (imitating opening the drawer and looking at the group)

Group: Clothes!

T1: Clothes! Ok. Then what would be in the third one? (imitating opening the drawer at the bottom).

Group: Shoes!

T1: Very good, there are shoes in the third drawer.

Two aspects of as-is and imaginary as-if can be distinguished from participants' perception of the character's I-world relationship: the as-is aspect of I-in-room and the as-if aspect of being rich. The two aspects are in tension and function as a powerful force sustaining participants' imagination and meaning making process. As-is and as-if are not in a static separating and contracting condition, but in a dynamic, intensive and dialogical relationships as $\{\mathrm{A}$ and (tension-filled relation with) non-A\} (Valsiner, 2012b). The inter-relatedness between the dual opposites and the tension within the duality opens a space for the emergence of various relations between the two, and has the potential to transcend the previous structure. Abbey (2007) conceptualizes the innovative synthesis from the tension between as-is and imaginary 
as-if as poetic action. Poetic action has the power to project itself to the future and mediate the present (Abbey \& Bastos, 2014). However, the dynamic relationship between as-is and as-if can also remain in a mutual-feeding form without producing poetic action for further development. As seen in the segment \#1 constructing the room, the participants imagined one million Yuan in the room and quickly go back to reality (100 Yuan) faced with teacher's challenge. After class, they continued talk about fraudulent advertisements promising job opportunities with high salary. The mutual-feeding relationship can be structured as: There are opportunities to be rich- but it is not true- but.... (Fig. $5)$ :

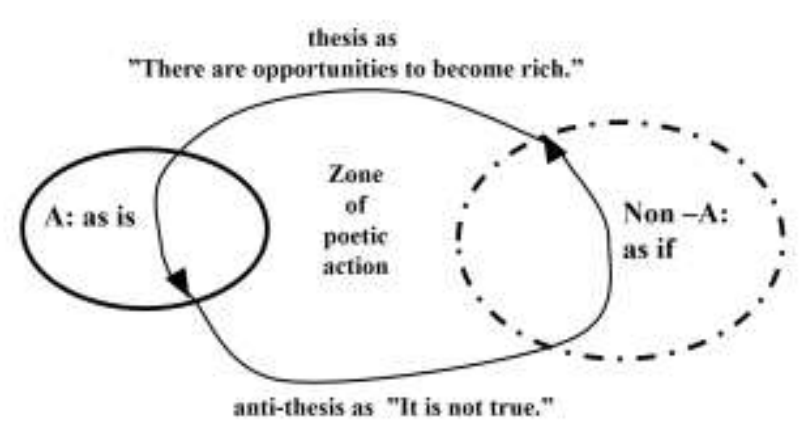

Fig 5. Mutual-feeding relationship between as-is and as-if

The scene performed by teacher in role also has the as-is and as-if aspects of I-world relationship as its center. The man character enters from outside; locks himself inside; looks outside the window; looks inside the dream box; and reads the newspaper getting information and communicating with the outside. He tries, gets frustrated, tries again and gets frustrated again. The as-is part is reinforced and intensified in the performance, which breaks the mutual-feeding circle and leads to an affective generalization of I-living-in-the-world as "alone", "fretful" and "depressed". After the performance, T1 stayed still in the room and T2 stood outside the room as facilitator and asked the group what happened and what did they see. The transcript of interaction between T2 and the group follows:

T2: "What happened? What did you see? You can try to enter the room."

BZ: (imitating opening the door and walking into the room, pointing to the cookies and talking towards the group) "I saw a pack of cookies he hasn't finished but very cherished. (Bending down to look the newspaper) and also job information on the newspaper and job information he wrote down"(imitating opening the door and walking out).

T2: Good. What else do you see?

BJ: (imitating opening the door and walking inside, scratching his head and looking around the room) "I see, the main character sitting here alone, very fretful. And... (Looking towards T2) outside the window, everything is still so lively. But he himself in the room, the atmosphere is very depressing. Garbage all around the room (Waking out and closing the door).

T2: “Good. What happened do you think in the performance? What happened?"

BZ: "He has no clue. "

T2: "No clue." 
PJ: "The landlord comes asking for rent. Very depressing."

The one-side strengthening of the as-is part cannot dismiss the as-if pole and eliminate the tension state, as the two opposites of as-is and as-if are obligatorily and permanently united within a whole. In the following enacting part, performed by three participants BJ, WS and PJ, one can see that strengthening and domination of as-is leads to accumulated emotional tension, which outburst in the dramatic event of the character tearing the newspaper (Fig. 6):

BJ: (rubbing his hair madly, tearing the newspaper with a low roaring, and throwing the pieces onto the floor.)

T2: what were you thinking when tearing the newspaper?

BJ: I was thinking nothing, just very angry.

T2: Very angry. Why angry?

BJ: Because pressure from life, and other various reasons. Cannot figure it out. Thus very angry.

WS: (slowly flipping the newspaper, pause, tearing the newspaper, pause)

T2: what were you thinking when tearing newspaper?

WS: Thinking......

T2: Why would you tear the newspaper?

WS: Looking at those... those jobs, He has gone to the interviews. After interview, didn't make it. His previous dream, nothing has been realized now. Now came to a unfamiliar city. Just for one month? T2: (nodding)

WS: just for one month. Now looking for jobs, having nothing. In such a small room...(pointing to the cookies, cant hear the content clearly).......down-and-out till now.

PJ: (reading and flipping the newspaper, tearing and throwing it to the floor angrily, sitting there with head down)

T2: Why tearing newspaper in that way?

PJ: mainly because, there are many jobs on the job information, but lots of them don't fit him. Not easy to find something suitable for him. So very angry and he tore them. 


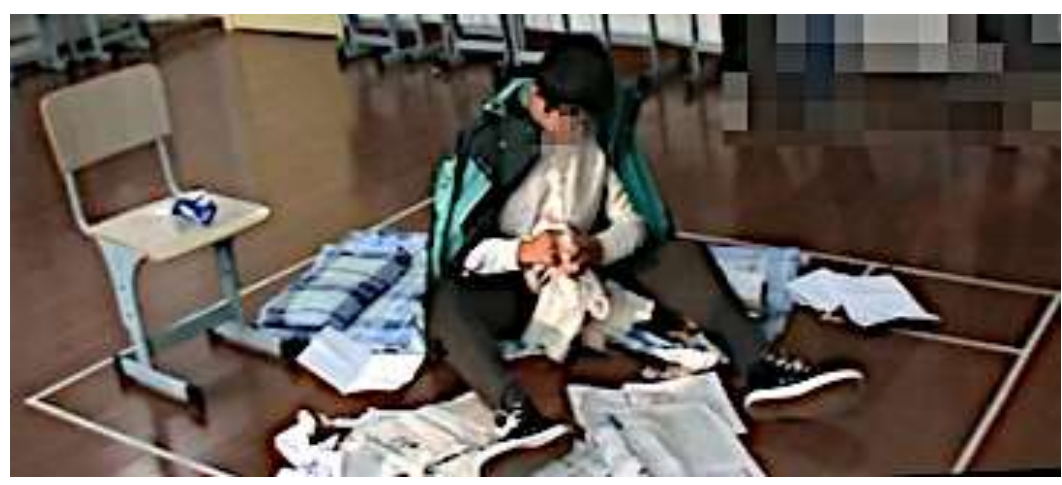

Fig. 6 WS enacting tearing the newspaper

By enacting the dramatic event of tearing newspaper, participants experienced vividly character's emotional tension reaching a breaking point. The three volunteering participants interpreted the burning out of I-living-in-the-world in three different ways: as helpless not being able to "figure it out", as down-and-out and as trying to "find something suitable". These three different semiotic paths are valuable personal voices and resources, which can be further knitted, thickened and explored by the group. This "breaking through" is like "short circuiting” in Vygotsky's term (Vygotsky, 1925). Valsiner (2015) analyzed Vygotsky's use of the simile of "short circuiting" in explaining the generalization of affective abstraction and he pointed out that there is a bifurcation of outcomes following "short circuiting": affective generalization or destruction of affects. In the direction of affective generalization, qualitatively new feelings are synthesized, while in the other direction, no affect is left and the individual is left in a blank area. Fig. 7 describes the semiotic process of how the affective generalizing field of "depressing” internalized from teacher's performance strengthening the dominance of as-is world on the as-if world, leading to an accumulating tensional state, and burning out when reaching a breaking point. It can be seen from the participants' enactment, that the opposition between hopeful trying and frustration was simply destructed and destroyed in anger.

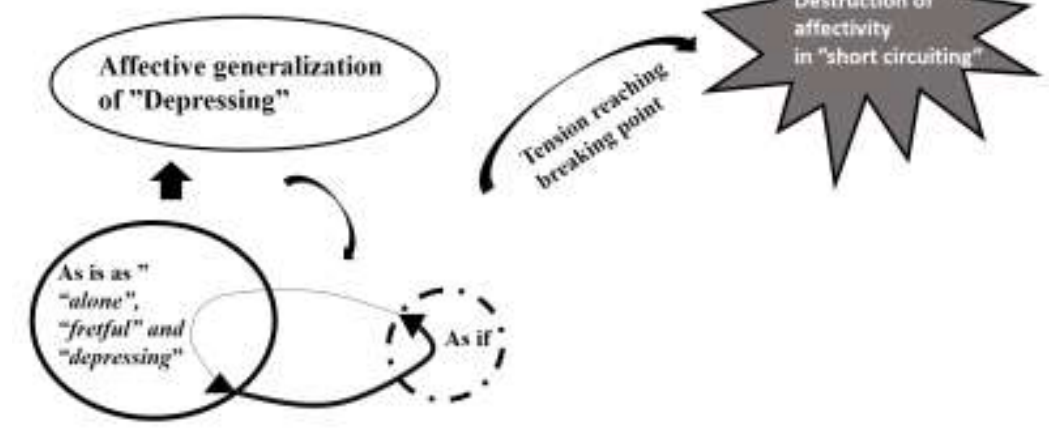

Fig. 7 Burning put of tension arising from as-is dominating as-if

The first three episodes of the workshop began with a mutual-feeding relationship between as-is and imaginary as-if, went through a strengthening phase of as-is world trying to dominate as-if and ended with a clashing and burning out of opposite affects. In the next part, we will see how this burning out steams out emotions and leaves space for narrative 
gestalt of "dream" to generate powerful affective abstraction integrating and reconstructing past, present and future, and how different personal voices are unified in this strong conventional atmosphere.

\section{Part 2 Affective abstraction under narrative gestalt: "Fighting for dream"}

The second part started from the \#4 episode of narrating the day he left home and ended at \#5 episode of using tableau to construct what would happen two months later and one year later. A timeline of past and future was marked on the floor with tapes extending from two corners of the room. T1 used "box" as the key object to thread the \#4 episode with the previous ones: the box as the object the character brought with when he left home. Three participants (BZ, CY and $\mathrm{XLB}$ ) volunteered to step onto the past timeline, hold the box and narrate the moment of leaving home. Following is their narrative construction under T1's guidance. In their narration, the box was abstracted and referred to equally as "dream": "with his favorite box, with his dream", "dream related stuff into this box". The abstraction of box to dream powerfully launched participants into the cultural conventional world of "dream" and significantly transformed participants' perception and construction of the as-is world from being "depressing" to "fighting" for dream:

T1: "Let's walk along the timeline and back to the day he left home. What story happened between him and the box? What is the connection? Can you imagine? How did he left with this box? Next, I will invite some of you, to stand on the time line, hold the box and narrate what happened the day he left home. You can say whatever you imagined."

BZ: "That day, his mother bought him a train ticket, a ticket to that city, and also gave him some money. She told him to work hard there. He set out with his dream, felt the future is very beautiful, with his favorite box, with his dream to fight for."

CY: "Just graduated from university, and then out, out looking for job, and with hopes and fantasy towards another city, he..."

XLB: (Silence)

T1: "you feel it was in the morning, or noon or afternoon? What time?"

XLB: "Should be in the morning?"

T1: "What's the situation, anyone discovered him?"

XLB: "Should be he alone. He put all his important stuff, dream related stuff into this box. And then took some money, went out by himself, fighting in the society."

T1: "Early morning, alone in a rush, with this box"

XLB: Yes, with the box, with his dream. 
The third interaction between T1 and XLB showed a co-constructing process of a scene as specimen in the conventional narrative gestalt of "dream". Tateo (2019) analyzed art generalization as creating "an abductive specimen of humanity: the person in the society as well as the society in the person" (p. 150). He also pointed out that the thick representation of specimen enables people to affectively relate to human experience, instantly grasp the wholeness of the experiential field, and have a better understating of mundane life. It is worth noting that the last sentence by T1 in this interaction- "early morning, alone in a rush, with this box" - is not an inductive summary of participant's given information. Rather, the teacher re-constructed and abstracted XLB's input in an abductive way into an affective specimen for the group to grasp the whole existential field in the strongest form. In the powerful zone of estrangement launched by the co-constructed abductive specimen (Tateo, 2019), we can almost see a typical scene happening in front of us in a sorrowful but also excited and bright atmosphere. This is a scene of "leaving home for dream" and it can be narrated conventionally as follow:

"He has nothing to himself at that time. He took all his stuff and the box, set off to another city. He left maybe in a morning, a very cold winter morning. It was very early, still dark. His family companied him to the station. He got on the train, sat himself beside the window, held the box on his lap and weaved goodbye to his family. As the train started, his family, along with the view of the station, slowly went back, until they could hardly be seen. The sky slowly brightened, and he felt his eyes blurred with tears."

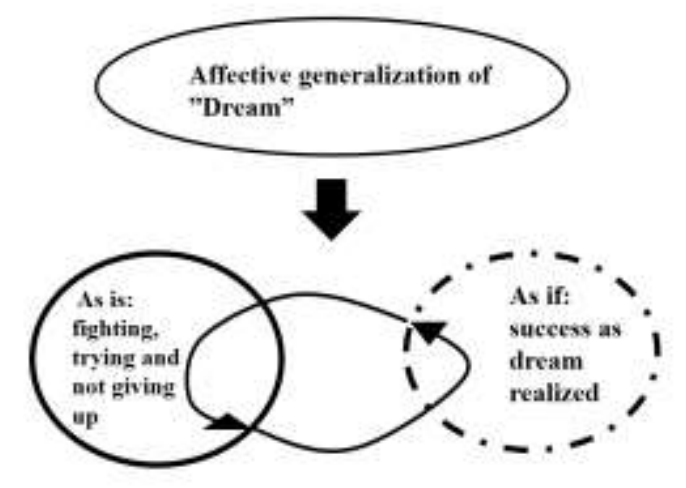

Fig. 8 Re-construction of as-is and as-if mediated by affective generalization of "dream"

Narrating what happened the day he left home triggered the gestalt of "dream" and empowered participants to enter into the corresponding affective generalization. The "dream" narrative is conventionally constituted by three parts: departing home to a new place with fear, sorrow and hope - totally different reality, faced with stress and frustrationsfighting until dream being realized. The narrative gestalt of dream immediately dominates the blank affective field left by the burning out. It emerges from the wound of burning out and functions as a poetic healing process striving for resuming and re-construction. The "Dream" gestalt enables participants to re-interpret the as-is world and also channels the as-if future by providing entrance points to alternative life trajectories (Fig. 8). In \#5 episode of using tableau to construct the future, feelings of helpfulness, depression and frustration are replaced by a positive state of "not giving up" and "trying". The contents of tableaus and interaction between T2 and the group are summarized as follow: 
(Sub-group 1 created a tableau showing that two months later, he is delivering food)

T2: Why does it happen?

Sub-group 1: Because it is easier to find, not many requirements, as long as you can ride an electric motorcycle and have a phone.

(Sub-group 1 created a tableau showing that one year later, he is interviewing for a job).

T2: Why does this change happen?

Sub-group 1: Because at first he found a job to support himself. He had to choose something he didn't like. Later it became better and better. He has had the capital and he wants to transfer to the jobs he likes.

(Sub-group 2 created a tableau showing he is interviewing for a job two months later.)

T2: Why does it happen?

Sub-group 2: He tried other jobs relating to his interest and goes to an interview. In the interview, he has to compete with another interviewee who has much higher educational qualification and much richer experience. He finally gets the job because he is sincere and he shows his attitude of really wanting to do a good job.

(Sub-group 2 created a tableau that one year later, he gives flower to a girl and expresses his love to her.)

T2: (asking the other two sub-groups as audience) Two months later, he found a job. One year later, he expressed love to the girl he liked. Do you think it would happen?

Audience group: Yes.

$\mathrm{PJ}$ : Everything is possible

T2: why does it happen?

Sub-group2: Because things are going better. First finding a job. After his efforts, he brings her to see his parents.

(Sub-group 3 created a tableau showing that two months later, he is celebrating for getting a job with new friends).

T: Why does this change happen?

Sub-group 3: He doesn't give up his hopes, tries to find part-time jobs.

(Sub-group 3 created a tableau showing that one year later, he succeeds and is signing contracts)

T: Why does this change happen?

WS in sub-group 3: (Looking towards the room and narrating) It is very hard to walk to this step, one step by one step forward. He has gone through all these ups and downs. He feels it is really not easy to arrive at this step, and is very proud of himself. Looking back at that room, really not easy. At that 


\section{time, he only has that simple small room, but now he has his house, he starts his business and fight} with his sweat.

It can be seen that \#5 segment of constructing the near future moved away from the field of affectively abstractive generalization to consider more realistic factors and possibilities: to start with part-time jobs and try something with lower requirement. The meaning of the symbol "dream realized" evolves in this segment and is projected into more secular success in multiple ways: getting favorable jobs, buying house and starting own business. Constructing the future functions like a rehearsal for real life challenges and the group actively imagines alternative trajectories under different practices leading to success.

The visualization of the room and its extended timeline also helped participants to look back upon past and present from future, and integrate the three into a narrative gestalt. As can be seen in WS's construction in sub-group 3, the spatial setting of a long timeline activated WS's perception of life as a journey: going through "one step by one step" and "ups and downs" to "arrive at this step". In the light of dream realized and success achieved, all the hard work and ups-and-downs are re-evaluated and appreciated as "fighting": a necessary path toward a desirable state. In this way, the narrative gestalt of "dream" gives birth to an implicit storyline: working, trying and fighting hard to achieve success.

\section{Part 3 From affective generalization to hyper-generalization: relating dream to values}

The narrative gestalt of "dream" in part 2 successfully involves participants into a level of affective generalization and also opens space for projective contextualization in constructing future scenes. The following part consists the last two segments of poetic narration and writing a letter for reflection. In poetic narration, an artistic figure of a little boy enjoying building sand castle is constructed. T1 gathered the group to sit down at one side of the room (Fig. 9) and she sat in the room slowly and poetically narrating as below to ensure participants have time to see it with their imaginary eyes:

\footnotetext{
"Many years later, the man was seen sitting on a bench in a park and enjoying the sunny weather with his sunglasses on. Not far away from the bench, there was a little boy playing with sand. He was building a castle. He built, then tore it down, then built again, then tore it down again. The boy seemed very happy and concentrating. The man looked at the little boy for a long time and slowly, there was a smile coming in his face."
} 


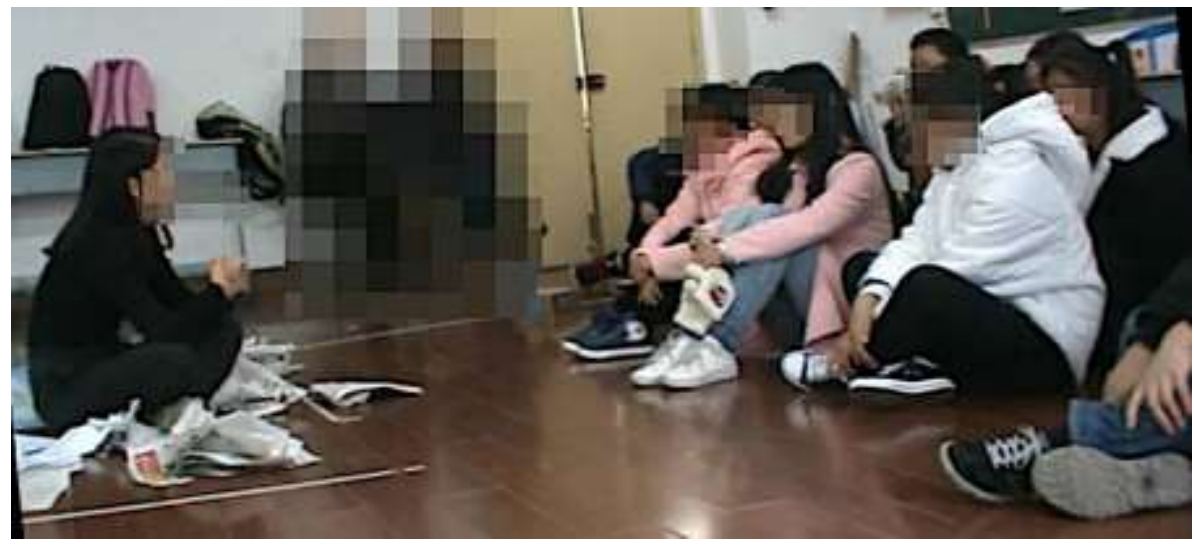

Fig. 9 Poetic narration on "little boy" by T1

The artistic figure of little boy frames and leads the participants back to the level of affective abstraction from the relatively lower generalized level of constructing the future. The figure "little boy" contains abundant possibilities for various kinds of affective generalization: It echoes the step-by-step work in the dream gestalt with the boy's repetitive construction and reconstruction, which resumes previous affective generalization. It also indicates a reconciliation with life by the boy's devotion into building with a playful and free attitude, which transcends the positive "dream" affective generalization. The last sentence of T1's narration- "The man looked at the little boy for a long time and slowly, there was a smile coming in his face”- opens up a space for inner dialogue and facilitates participants to actively make meanings both cognitively and affectively to fill the void.

Affective generalization growing from the artistic figure of "little boy" also paves its way to further generalization in written language in the last segment of writing a letter. The letters all began with a given expression of "Dear self" and participants were required to write from the perspective of the man to himself at a past/present/future point of time. The teacher invited the participants to put their letters on the timelines when they finished and she picked up some randomly to share with the whole group. Most letters were addressed to self in future and here we analyze three of them:

Letter 1: “Dear self, perhaps you wouldn't be able to foresee. Looking at the past, just coming to this city, no car and no house yet, no clue, no aim. Looking at yourself at that time, feeling everything unsatisfied about self. Very ironclad. Perhaps dream, just like that little boy, you may not do well, but as long as you are willing, to try over and over again, never give up, and only then today comes, as broad as the sea and sky."

Letter 2: "Dear self, think about that time, self has been working so hard, one step by one step, keep going. Although having been dispirited, but because of dream, because of persistence, it is succeeded today. In fact, all the things are the same. Without persistence, from where would come success?" Letter 3: "Dear self, optimism +confidence +persistence=success. The future is very bitter, but also very beautiful." 
Addressing from the perspective of man to himself increases psychological distance and creates a safe zone to express their deep feelings and understandings at the end of this journey. The letters represent characteristics of poems, in which rich emotions are expressed in short and rhythmic sentences. The dynamic in the phrases of "try over and over again" and "one step by one step" echoes the rhythm in little boy's repetitive action of building and tearing down and also reflects the spatial setting of the room in the timeline. The above three letters are chosen for analysis as they represent two different levels of affective generalization:

1) Affective generalization through metaphoric extension of "little boy". The first letter shows the process of how the field of affective generalization empowered by the art figure of "little boy" prominently reconstructs participants" perception of present living condition. In the metaphor of "little boy" exists a warm, bright and conciliatory affective field of "appreciating and enjoying the process", which drives a poetic narrative reconstruction of the present situation as a "willing" and "trying" process towards a state "as broad as the sea and sky."

2) Construction from affective generalization to hyper-generalization. The second letter starts from the positive reconstruction of present living condition under the affective generalization of "dream", as the first one. The last two sentences- "In fact, all the things are the same. Without persistence, from where would come success?" - indicates an insightful qualitative leap: transcendence of the negative-positive perception and moving to the field of further hypergeneralization of values. The "in fact" moment shows the synthesis process of affective generalization to hypergeneralization: from being persistent and working hard with continuous step-by-step effort to the value of "PERSISTENCE". Hyper-generalization of values is also shown in the value equation of the third letter, in which "SUCCESS" is related to values of "OPTIMISM", "CONFIDENCE” and "PERSISTENCE" (Fig. 10).

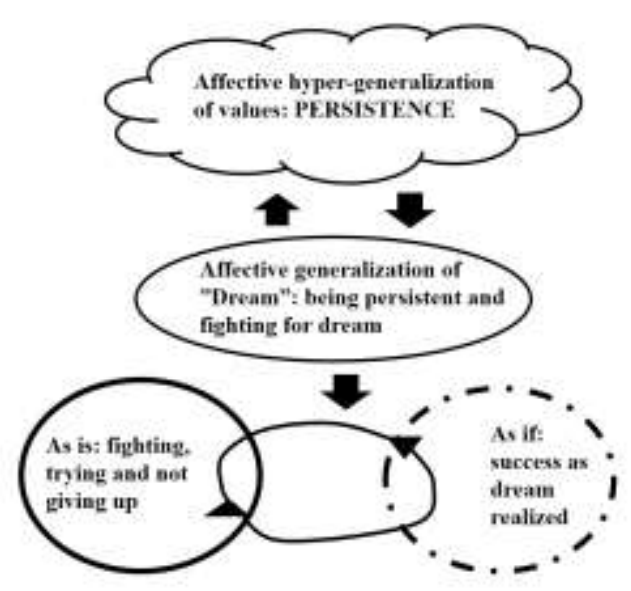

Fig. 10 From affective generalization to hyper-generalization: construction of values

As Valsiner (2019) has pointed out, “Affective hyper-generalization is the highest level of human cultural existence- in devotion, ideologization, and life-long commitment to values (p. 453)." We can use Valsiner's (2015) introduction of "double negation" into psychology to better understand the qualitative transformation from affective generalization to hyper-generalization: 


\begin{abstract}
"In dialectical philosophy the notion of negation is presented in the form of two mutually linked processes of negation. The primary negation ('A is not $B$ ') is crucial in classical logic where it is the root for all further logical derivations. Yet it is only the basis of its own negation - the negation of the first negation ('the claim "A is not $B$ " is irrelevant'). This second negation reunites the previously separated opposites. It creates the possibility to look at the systemic functioning of parts within a whole (p. 99)."
\end{abstract}

The re-constructive narration of past and present under the affective generalization enabled by "dream" constitutes a first negation of the original depressing perception of life. The insightful "in fact" moment is a qualitative jump, a double negation- "negation of the first negation", which units the two separated opposites of being negative and positive, and transcends to a deep grasping and appreciation of the value of "PERSISTENCE". Both negative and positive attitudes are object-bounded and deeply affected by concrete situations. Moving into the hyper-generated affective field of value enables to get rid of the burden of concrete objects, and it wins us a feeling of becoming free by transcending the finite human life into infinite values. Entering into the hyper-generated affective field also powerfully mediates our perception and construction of the real mundane life.

\title{
Discussion
}

The two-hour workshop "Castle in a box", from warm up to final reflection, constitutes a coherent and integrative experience in Dewey's sense for participants. The episodes are selectively designed to empower and guide participants to release and transform their developmental forces into dramatic configuration, the sensuous materiality of which opens room for further generalization and reflection. In this example, DiE becomes a safe zone for participants to explore meanings, as it allows participants to decide to which degree they want be involved. Both "living through" in roles and observing out of roles has the potential to facilitate meaning production. So far, we have closely looked into participants' semiotic flow among different levels of generalization in these episodes. Fig.11 provides an overview of the dynamic evolving process of participants' semiotic construction in the workshop. The semiotic flow started with a mutual-feeding relationship between as-is and imaginary as-if, which was broken by the teacher-in-role performance with an affective atmosphere of "depressing”. Mediated by the affective generalization of "depressing", the as-is aspect of I-world relationship was strengthened and gradually dominated and inhibited the as-if aspect until the tension reached a breaking point and destructed all the affects. Narrative gestalt "dream" emerged as an abstraction from the key object box in imagining the past. It worked as a gestalt narration and triggered a powerful affective generalization field, re-organized the blank area left by the burning out and re-constructed narrations on the as-is present and as-if future into "fighting and trying until dream realized and success achieved." The artistic figure of "little boy" pulled participants back to the affective generalization field under dream, which also prepared for further abstraction into affective hyper-generalization of values. 


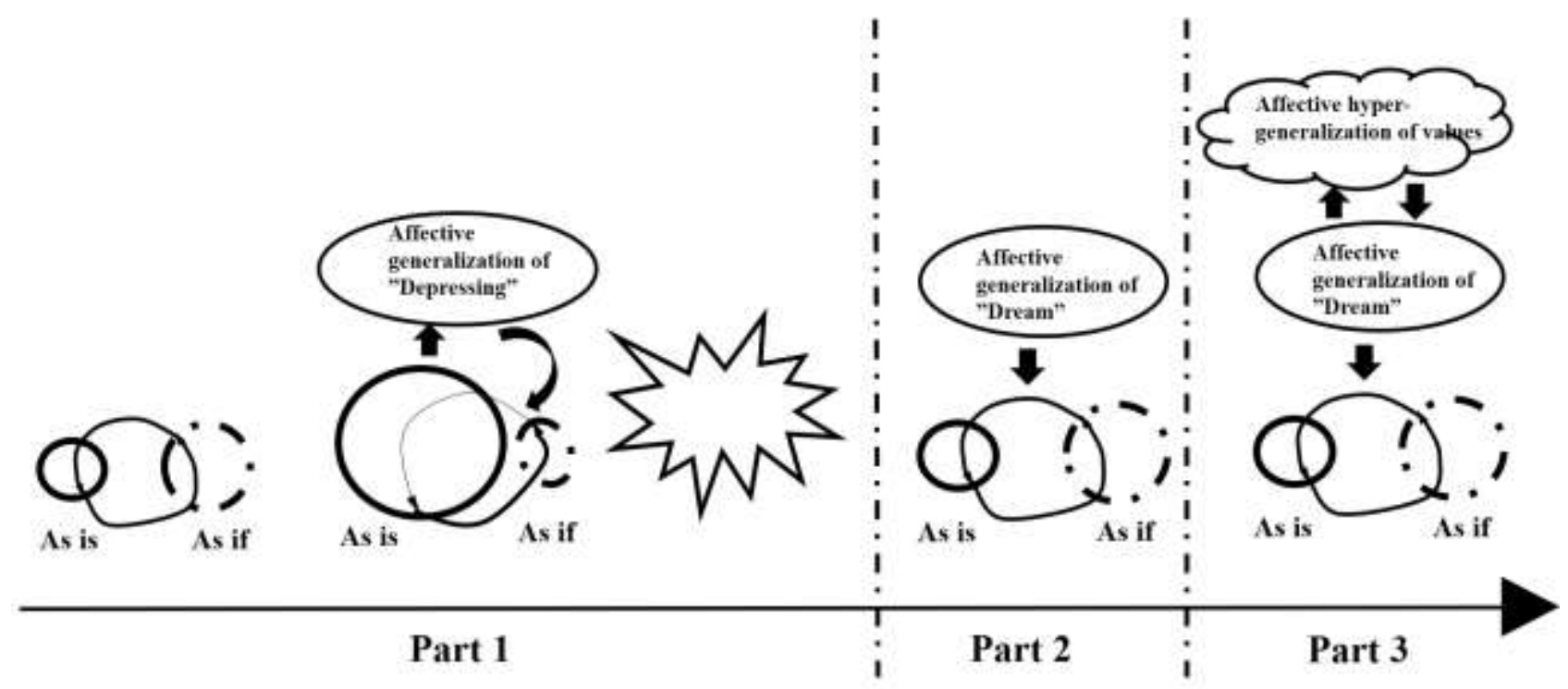

Fig. 11 Participants' semiotic flow in "Castle in a box"

The therapeutic escalation from being depressing to poetic generalization happens in episodes of enacting tearing the newspaper, construction of the past and future and reflection in a letter. These episodes contains different mixing forms of I-as-I and I-as if- the character experiences. To be more specific, in the enactment, participants can enter into the role and then reflect out of role. Entrance into the role gives participants a real taste of the dramatic event, release their emotions and pushes the group into an urgent state of seeking meaning for the future. In the episode of narrating the past, participants are invited to step on the timeline, hold the box, and tell the story of him at the day he leaves home. Thus, participants embody the character but narrate the story in a distanced mode- a mixed experience of I- as-I and I-as if-the character with a mixing degree of imagination and non-imagination. This balance between "living through" and "distancing", is critical for the emergence of affective generalization of "dream", as it is close enough to involve participants affectively while also distanced enough not to embarrass them. In the episode of constructing the future and writing a letter, the "he" perspective is also emphasized in teacher's facilitation- what would happen to him? What would he say to himself- to distance and protect participants from strong emotions and also to prevent potential resistance, as the story designed for the workshop is relatively close to participants' real life experiences. As Dewey (1934) as pointed out, "Insufficient emotion shows itself in a coldly "correct" product. Excessive emotion obstructs the necessary elaboration and definition of parts (p.70)", transitions between I-as-I and I-as if-the character and a delicate mixing between the two is crucial for participants to feel into the imaginary world and transform their developmental forces in the workshop.

In this semiotic flow, two interesting characteristics deserve careful discussion: 1) narrative gestalt of "Dream" as a powerful semiotic device for the group; 2) The implicit storyline under dream as "persistently fighting for success" and emergence of value "PERSISTENCE".

Narrative Gestalt "Dream" as a powerful semiotic device for the group 
It can be seen in the analysis that the narrative gestalt of "dream" enrolled the group quickly. This gestalt includes substories as its structured contents and an affective generalizing field as its feeling tone. Participants adopted languages from dream's three-step narration model: departing home to a new place with fear, sorrow and hope - totally different reality, faced with stress and frustrations-fighting until dream being realized, and implicitly developed a storyline of "Work, try and fight hard, and success will be achieved”. Mortola (1999, p. 308) pointed out that, "the important shared concept at the heart of both Gestalt theory and narrative theory is that we are constantly addressing and attempting to make sense of "disequilibrium" in our experience." The "dream" gestalt, together with the visual gestalt of the room and the timeline, integrate scattered and out-of-balance experiences into a cohesive whole and from this newly synthesized whole, experiences are re-placed, re-narrated, re-evaluated and endowed with new meaning. Entering the affective generalizing field of "dream" enabled a transformation from the heaviness of life to its lightness quite smoothly after the dramatic burning out. In the blank area left by burning out, narrative gestalts as cultural modes provide us templates, models and paradigms to organize and reclassify social experience and mediates our relationship to others and to ourselves (Turner, 1982). Introducing the "dream" narrative gestalt has two-side effects. On one hand, it synthesizes previous opposites into a meaningful whole, and from within the gestalt frame grows positive perspectives and alternative trajectories for development, which are unvoiced in participants' spontaneous narration. On the other hand, it also brings a closure to further narration and narrows down the potential for deeper exploration. Under the structuring power of narrative gestalt, unique personal modes are covered and faded away into the background (Xu, Li \& Wang, 2018).

We can use Kundera's (1984) thinking on "Kitsch" in his novel "The Unbearable Lightness of Being" to understand this mechanism. According to Kundera, kitsch is derived from human's basic impression engraved on human's memories. It contains "certainties and simple truths to make the multitudes understand, to provoke collective tears (p.270)", and it "excludes everything from its purview which is essentially unacceptable in human experience (p.264)." In the realm of kitsch, there is no disagreement between cognition and emotion. Individuals become moved in strong but smooth and safe affective atmosphere. It is smooth and safe as people are sure that they are moved with all humankind. In this way, kitsch is a fragile dream, a beautiful lie about the life reality. Kundera called it "a folding screen set up to curtain off death (p.270)":

"In the realm of totalitarian kitsch, all answers are given in advance and preclude any questions. It follows, then, that the true opponent of totalitarian kitsch is the person who ask questions. A question is like a knife that slices through the stage backdrop and gives us a look at what lies hidden behind it (p.270)."

In the narrative gestalt of "dream", the core is "Work, try and fight hard, and success will be achieved". By entering this gestalt, the group are inspired, motivated and united into one. The "dream" gestalt temporarily creates a liminoid space for them to have a break and refresh themselves. It is especially powerful as it is a group liminoid, in which the conventional discourse strengthens, echoes, and finally resonates into a strong affective generalizing atmosphere. In DiE participants are rehearsing for real life challenges. When real life enters the stage, the semiotic power carried by the narrative gestalt of "dream" may be thickened, flourished and even replaced by more personal motivations, intentions and desires. These motivations and desires emerge from being 
in the world as a sensuous social being (Wang, 2016). It is “sensuous consciousness” in Marx”s historical materialism and "a sense of possibilities that are unrealized and that might be realized" in Dewey (1934)'s term, that "When they are put in contrast with actual conditions, the most penetrating "criticism" of the latter that can be made. It is by a sense of possibilities opening before us that we become aware of constrictions that hem us in and of burdens that oppress. (p. 346)"

\section{Implicit storyline as "persistently fighting for success" and emergence of value "PERSISTENCE"}

As pointed out above, underlying the "dream" gestalt there is an implicit but prominent storyline of "fighting and not giving up leading to success". The storyline is further abstracted into hyper-generalized affective field of value "PERSISTENCE". The relation between value "PERSISTENCE" and dream also deserves a careful discussion. "PERSISTENCE" is an individualized value, different from “LOVE" or "FRIENDSHIP”. It emphasizes more on individual's own efforts to change present condition. Construction of value "PERSISTENCE" is closely connected to and highly appreciated in Chinese tradition. In the book of changes, striving continuously for self-strengthening is as equally important as being broad-minded and caring, which together constitute basic virtues for Chinese society: "Just as heaven keeps moving forward vigorously, a man of virtue should strive continuously to strengthen himself (Key concepts in Chinese thoughts and culture, n.d.1)." "Just like the earth, which is generous and peaceful, a man of virtue should have ample virtue and accommodate all things (Key concepts in Chinese thoughts and culture, n.d.2).” Also, migrating from villages in rural China, young people lose their original close connections with their communities and experience themselves as isolated individuals without rich resources to prepare for the future. With an expectation of all the difficulties, the "dream" gestalt and value of "PERSISTENCE" helps them to mediate themselves in their relationship with the social world.

The workshop was designed in the group's transition period from NGO training to job interview, when they had to complete an identity change from student to labor in the job market. An interesting following research would be how the affective generalization of "dream" and "PERSISTENCE" continue to function as a symbolic mediation device in comparison with other social discourses gradually emerging in Chinese social life. For example, young labor are "chives" which continuing to grow after being cut by the capital market, or "batteries" as being thrown away when used up by big companies. Social inequality, fierce competition and narrower and narrower space for class mobility is the social reality in modern China. Wang pointed out how capital simplifies life meaning and reduces human values into materials for its own self-expansion: "Every individual's life is no longer his own life. It is a path set by the modern social machine (Wang, 2005b, p. 9)". He also stressed that there exists tension between Western capital principal and Chinese cultural spirit, and it is most obvious in Chinese's emphasis on their next generation:

"Even today with flourishing western influences, Chinese still attach great importance to their next generations and regard them as their lifeblood. This is a symbol of their "having destiny". Chinese wont believe that their success earned in this life only has the value of satisfying their personal material desires or for abstract self-realization. Almost "following their nature", Chinese request themselves to use their wealth to open up a bright and happy road for their next generation. This goal still has a meaning of ultimate care of life for today's Chinese (Wang, 2005b, p.10)." 
Wang emphasized on the ultimate meaning of making a better life for next generation for Chinese. From this, we are touching a unique question of what makes Chinese and this question is most clearly revealed by their encountering with the capitalized society: their understanding of and their dealing with their destiny. It is ultimate as it reaches the existential question of what is meaningful in life. In this workshop, the narrative gestalt of “dream", its evolving storyline of "persistently fighting for success", and the hyper-generated value of "PERSISTENCE" are activated and produced by the group to identify themselves in their developmental transitions upon the background of the present industrialized society. At the end, not only class problems, but also ultimate existential questions, would constitute strong driving forces for semiotic construction. It challenges our highest psychological functions to illuminate our existence in the holes sliced by the knife of most painful and struggling moments of living in the world.

\section{General conclusion}

Imagining in drama is also imagining the real (Davis, 2014). The condensed and hybrid cultural-aesthetic experiences in DiE opens up a horizon of abundant phenomena for psychology to understand his subject with multi-layered existence. It is a developing subject striving for meaning to understand and express his existence as a sensuous social being caught by conflict, ambiguity, uncertainty and restrains in daily life (Lehmann \& Brinkmann, 2020). Development dramatizes itself from ground to mountain, from grape to wine, in the most poetic and freest form. Advancing and realizing DiE's potential as developmental and educational guidance requires inter-disciplinary joint efforts to integrate the most creative and fruitful researches from both areas. Based on Vygotsky's identification of the importance of "perezhivanie" for human development from his appreciation of theatre art (Veresov \& Fleer, 2016), introducing the theoretical lens of developmental cultural psychology into investigating DiE has helped us to move one step further: It is a step of going deep into participants' subjective dramatic experiences with signs as a basic unit preserving both personal and environmental characteristics. A micro-genetic analysis of the dynamic construction of participants' semiotic hierarchy in irreversible time arrests perezhivanie both as a content and as a process. What would be the next step?

\section{Reference}

Abbey, E. (2007). Perpetual uncertainty of cultural life: Becoming reality. In J. Valsiner, \& A. Rosa (Eds.), Cambridge handbook of socio-cultural psychology (pp. 362-372). Cambridge, NY: Cambridge University Press.

Abbey, E., \& Bastos, A. C. (2014). Creating bridges to the future: The poetic dimension through family life. Culture \& Psychology, 20(2), 232-243. https://doi.org/10.1177/1354067X14527840

Branco, A., \& Valsiner, J. (2010). Towards cultural psychology of affective processes: Semiotic regulation of dynamic fields. Estudios de Psicologia, 31(3), 243-251. https://doi.org/10.1174/021093910793154411

Bruner, J. S. (1986). Actual Minds, Possible Worlds, Cambridge, MA: Harvard University Press 
Dewey, J. (1934). Art as experience. New York: Minton, Balch, and Company.

Davis, D. (2014). Imagining the Real: Towards a New Theory of Drama in Education. Trentham Books.

Dewey, J. (1950). Aesthetic experience as a primary phase and as an artistic development. The Journal of Aesthetics and Art Criticism, 9(1), 56-58. https://doi.org/10.2307/426103

de Mattos, E., \& Chaves, A. M. (2013). Semiotic regulation through inhibitor signs: Creating a cycle of rigid meanings. Integrative Psychological and Behavioral Science, 47(1), 95-122. https://doi.org/10.1007/s12124$\underline{012-9223-x}$

DICE Consortium. (2010). Making a world of difference, A DICE resource for practitioners on educational theatre and drama. Retrieved from http://www.dramanetwork.eu/file/Education\%20Resource\%20long.pdf

Ganczarek, J., Hünefeldt, T. \& Olivetti Belardinelli, M. (2018). From “Einfühlung” to empathy: exploring the relationship between aesthetic and interpersonal experience. Cogn Process, 19, 141-145. https://doi.org/10.1007/s10339-018-0861-x

Heathcote, D. (1984). Collected writings on education and drama (L. Johnson \& C. O’Neill, Eds.). Evanston, IL: Hutchinson.

Heggstad, K.M. (2019). 7 paths to drama in education. (M. Y. Wang \& Z. Wang Trans.). East China Normal University Press

Key concepts in Chinese thoughts and culture. (n.d. 1). Retrieved November, 13, 2020, from https://www.chinesethought.cn/EN/shuyu_show.aspx?shuyu id=2325

Key concepts in Chinese thoughts and culture. (n.d. 2). Retrieved November, 13, 2020, from https://www.chinesethought.cn/EN/shuyu_show.aspx?shuyu_id=2254

Kundera, M. (1984). The unbearable lightness of being. (S. G. Han \& G. Han Tans.). Writers Publishing House.

Lehmann, O. V., \& Brinkmann, S. (2020). Revisiting "the art of being fragile": Why cultural psychology needs literature and poetry. Culture \& Psychology, 26(3), 417-433. https://doi.org/10.1177/1354067X19862183

Marsico, G., \& Tateo, L. (2017). Borders, tensegrity and development in dialogue. Integrative Psychological and Behavioral Science, 51(4), 536-556.

Mortola, P. (1999). Narrative Formation and Gestalt Closure: Helping Clients Make Sense of "Disequilibrium" Through Stories in the Therapeutic Setting. Gestalt Review, 3(4), 308-320.

O'Neill, C. (1995). Drama worlds: A framework for process drama. Heinemann Drama.Pascarella, F., Vicigrado, A., Tateo, L. \& Marsico, G. (submitted). Spontaneous dramatization as dialogical space in the school context, Human Arenas 
Rasmussen, B., \& Wright, P. R. (2001). The theatre workshop as educational space: How imagined reality is voiced and conceived. International Journal of Education \& the Arts, 2(2). http://researchrepository.murdoch.edu.au/id/eprint/3105

Tateo, L. (2019). Caravaggio's The Seven Works of Mercy and the Art of Generalization. In Subjectivity and Knowledge (pp. 141-156). Springer, Cham.

Tateo, L. (2020). A Theory of Imagining, Knowing, and Understanding. Cham: Springer.

Turner, V. (1982). Liminal to liminoid, in play, flow, and ritual: An essay in comparative symbology. In From Ritual to Theatre: The Human Seriousness of Play (pp.20-60). NY: PAJ publications

Valsiner, J. (2008). Open intransitivity cycles in development and education: Pathways to synthesis. European journal of psychology of education, 23(2), 131-147. https://doi.org/10.1007/BF03172741

Valsiner, J. (2012a). Oxford handbook of culture and psychology. NY: Oxford University Press.

Valsiner, J. (2012b). La dialéctica en el studio del desarrollo. In J. A. Castorina and M. Carretero (Eds), Desarrollo cognitive y educacíón. Vol 1. (pp. 138-162). Buenos Aires: Paidos.

Valsiner, J. (2015). The place for synthesis: Vygotsky's analysis of affective generalization. History of the human sciences, 28(2), 93-102. https://doi.org/10.1177/0952695114559530

Valsiner, J. (2018). Needed in psychology: Theoretical precision. Europe's journal of psychology, 14(1), 1-6. https://doi.org/10.5964/ejop.v14i1.1602

Valsiner, J. (2019). Culture \& psychology: 25 constructive years. Culture \& Psychology, 25(4), 429-469. https://doi.org/10.1177/1354067X19872358

Valsiner, J. (2020). Sensuality in human living: the cultural psychology of affect. Springer

Vassilieva, J., \& Zavershneva, E. (2020). Vygotsky’s "Height Psychology": Reenvisioning General Psychology in Dialogue With the Humanities and the Arts. Review of General Psychology, 24(1), 18-30. https://doi.org/10.1177/1089268020902723

Veresov, N., \& Fleer, M. (2016). Perezhivanie as a theoretical concept for researching young children's development. Mind, culture, and activity, 23(4), 325-335. https://doi.org/10.1080/10749039.2016.1186198

von Fircks, E. F. (2021). Daseinssemiosis: a New Look at the Phenomenology of Theodor Lipps. Human Arenas, 1-17. Vygotsky, L. S. (1925). The psychology of art, Cambridge, MA: MIT Press

Wang, D. F. (2005a). Philosophy of art. Fudan University Press.

Wang, D. F. (2005b). On the tension between the Chinese cultural spirit and the Western capital principle. Journal of Shanghai Normal University (Philosophy \& Social Sciences Edition), 34 (6), 1-10. 
Wang, D. F. (2016). On Marx's concept of sensuous consciousness. Journal of Yunnan University (Social Sciences Edition), 5, 3-8.

Wang, J. (2018). Construction of Jiti for students' active development- an interventional research in the charitable vocational training program. East China Normal University: Master's degree thesis.

Xu, S. S., Li, X. W \& Wang, J. (2018). "Castle in Box": How Immersion and Rational Reflection Work Together for Effective Intervention. In Brown, S., \& Tateo, L. (Eds.). The method of imagination. IAP. 143-152.

Zittoun, T. (2012). On the emergence of the subject. Integrative Psychological and Behavioral Science, 43 (3), $259-273$. https://doi.org/10.1007/s12124-012-9203-1 